\title{
Response of hPDLSCs on 3D printed PCL/PLGA composite scaffolds in vitro
}

\author{
CAIXIA PENG, JINXUAN ZHENG, DONGRU CHEN, XUEQIN ZHANG, \\ LIDI DENG, ZHENGYUAN CHEN and LIPING WU
}

\begin{abstract}
Department of Orthodontics, Guanghua School of Stomatology, Guangdong Provincial Key Laboratory of Stomatology, Sun Yat-sen University, Guangzhou, Guangdong 510055, P.R. China
\end{abstract}

Received November 24, 2017; Accepted April 13, 2018

DOI: $10.3892 / \mathrm{mmr} .2018 .9076$

\begin{abstract}
Three-dimensional printed (3DP) scaffolds have become an excellent resource in alveolar bone regeneration. However, selecting suitable printable materials remains a challenge. In the present study, 3DP scaffolds were fabricated using three different ratios of poly ( $\varepsilon$-caprolactone) (PCL) and poly-lactic-co-glycolic acid (PLGA), which were 0.1PCL/0.9PLGA, 0.5PCL/0.5PLGA and 0.9PCL/0.1PLGA. The surface characteristics and degradative properties of the scaffolds, and the response of human periodontal ligament stem cells (hPDLSCs) on the scaffolds, were assessed to examine the preferable ratio of PCL and PLGA for alveolar bone regeneration. The results demonstrated that the increased proportion of PLGA markedly accelerated the degradation, smoothed the surface and increased the wettability of the hybrid scaffold. Furthermore, the flow cytometry and Cell Counting Kit-8 assay revealed that the adhesion and proliferation of hPDLSCs were markedlyincreased on the 0.5PCL/0.5PLGA and 0.1PCL/0.9PLGA scaffolds. Additionally, the alkaline phosphatase activity detection and reverse-transcription quantitative polymerase chain reaction demonstrated that the hPDLSCs on the 0.5PCL/0.5PLGA scaffold exhibited the best osteogenic capacity. Consequently, PCL/PLGA composite scaffolds may represent a candidate focus for future bone regeneration studies, and the $0.5 \mathrm{PCL} / 0.5 \mathrm{PLGA}$ scaffold demonstrated the best bio-response from the hPDLSCs.
\end{abstract}

Correspondence to: Dr Liping Wu, Department of Orthodontics, Guanghua School of Stomatology, Guangdong Provincial Key Laboratory of Stomatology, Sun Yat-sen University, 56 Lingyuanxi Road, Guangzhou, Guangdong 510055, P.R. China

E-mail:wulping@mail.sysu.edu.cn

Key words: 3-dimensional printed scaffold, poly ( $\varepsilon$-caprolactone), poly-lactic-co-glycolic acid, human periodontal ligament stem cells, alveolar bone regeneration

\section{Introduction}

Alveolar bone defect is a common clinic issue, which may be caused by multiple factors, including inflammation, trauma, tumor, or congenital and developmental disorders (1). It may have a serious impact on chewing and pronunciation, and may even lead to serious facial dysfunction and deformities (2). Therefore, efficient alveolar bone restoration is required to restore function and appearance. Although bone grafts are commonly used in alveolar bone reconstruction, these methods have numerous drawbacks, including inducing new defects, immune rejections and potential infection (3).

Three-dimensional printed (3DP) scaffolds combined with osteogenic cells and/or osteo-inductive molecules have emerged as a promising alternative to grafts in bone tissue regeneration $(4,5)$. The fused deposition modeling (FDM) technique, a type of 3DP technique, has been successfully used in bone tissue engineering. Scaffolds are fabricated based on the extrusion of molten polymer fibers in a layer-by-layer manner, using the data collected from a computer-aided design program and computer-aided medical imaging including computed tomography or X-ray (6). Therefore, an FDM scaffold is able to highly match the external morphology of the defect and accurately restore the internal structure of the tissue, and thus represents a powerful approach for complex tissue engineering, particularly for cranio-maxillofacial constructs (1).

The ideal scaffold should be biodegradable and biocompatible. It should additionally possess a highly porous interconnected network with excellent surface characteristics for cell affinity and tissue regeneration (7). Selecting suitable materials for 3DP scaffold production remains challenging. U. S. Food and Drug Administration-approved synthetic polymers poly ( $\varepsilon$-caprolactone) (PCL) and poly-lactic-co-glycolic acid (PLGA) have the advantages of being relatively low cost, with the possibility of long-term storage and superior bioactivity, thus these polymers have received considerable attention in bone regeneration (8). PCL is flexible and used in various fabrication techniques; however, it has been demonstrated to have low degradability and inferior bioactivity (9). PLGA is hydrophilic, biodegradable and highly biocompatible; however, is more brittle $(10,11)$. The combined use of PCL and PLGA may overcome the shortcomings of single 
use and become an excellent biocompatible composite, which has been extensively applied in the clinic for various tissue restoration procedures (12-18). Previous studies have primarily focused on the biocompatibility of the PCL/PLGA composite scaffold; however, the biodegradable properties and surface characteristics of PCL/PLGA composite scaffolds have rarely been reported. Furthermore, few studies have examined the application of PCL/PLGA composite scaffold in alveolar bone regeneration.

Human periodontal ligament stem cells (hPDLSCs) possess immense potential in bone tissue engineering, owing to their various sources, easy attainability (19), high rates of proliferation, multi-lineage differentiation ability (20), and great capacity for alveolar bone (21) and tendon regeneration (22). In order to investigate a suitable material for alveolar bone regeneration, scaffolds with different ratios of PCL and PLGA were fabricated via 3DP and their surface characteristics and degradative properties, along with the response of hPDLSCs on these scaffolds, were subsequently assessed.

\section{Materials and methods}

Fabrication of PCL/PLGA scaffolds. The scaffolds were fabricated using a 3DP system (Bioplotter; EnvisionTEC GmbH, Gladbeck, Germany). PCL (molecular weight 50,000; Polysciences, Inc., Warrington, PA, USA) and PLGA (polylactic acid/polyglycolic acid 50:50; molecular weight 50,000-75,000; Sigma-Aldrich; Merck KGaA, Darmstadt, Germany) were used and the ratios of PCL/PLGA were 1:9, 5:5 and 9:1. The blended powder of PCL/PLGA was melted in a chamber at $130^{\circ} \mathrm{C}$, centrifuged at $100 \mathrm{x} \mathrm{g}$ for $10 \mathrm{~min}$ at a temperature range of $130-150^{\circ} \mathrm{C}$, and dispensed through a 27-gauge metal needle at $135^{\circ} \mathrm{C}$ to create fully interconnected structures with diameters and heights of 15 and $1 \mathrm{~mm}$, respectively. The XY dispensing head speed was $100 \mathrm{~mm} / \mathrm{min}$ and the dispensing pressure was $\sim 650 \mathrm{kPa}$.

Surface characteristics. The microscopic appearance of the scaffolds was observed using scanning electron microscopy (SEM; LEO 1530 variable pressure field emission SEM; Zeiss $\mathrm{GmbH}$, Jena, Germany) at a magnification of 75 and x1,000. The surface roughness of the scaffolds was determined using a profilometer of laser scanning confocal microscope (LSM700; Zeiss $\mathrm{GmbH}$ ) at a magnification of $\times 50$ and $\times 200$. The arithmetic average of the $3 \mathrm{D}$ roughness $(\mathrm{Sa})$ and the quadratic average of the $3 \mathrm{D}$ roughness $(\mathrm{Sq})$ was measured. The wettability of the scaffolds was evaluated by measuring the water contact angle (CA), using a CA video-based system (OCA15; DataPhysics, Filderstadt, Germany) and SCA20 software (version 1.0; DataPhysics).

Degradation characteristics. Scaffolds were cut into pieces weighing $50 \mathrm{mg}$ and were immersed separately in PBS (pH 7.4; Thermo Fisher Scientific, Inc., Waltham, MA, USA) at $37^{\circ} \mathrm{C}$ over 12 weeks. PBS was changed every 3 weeks. At 3, 6, 9 and 12 weeks, the scaffolds were removed, rinsed with distilled water and air-dried at room temperature for $24 \mathrm{~h}$. The weight loss was measured using a sensitive scale (ME103; Mettler-Toledo $\mathrm{GmbH}$, Greifense, Switzerland). The $\mathrm{pH}$ value of the PBS following removal of the scaffolds was measured using a pH meter (SevenMulti; Mettler-Toledo). Five specimens were examined for each scaffold at each time point and the average value was calculated and recorded.

Cell culture and identification. The protocol was approved by the Ethics Committee of the Hospital of Stomatology, Sun Yat-sen University (Guangzhou, China). Informed consent from each patient was obtained. A total of 16 healthy premolars were acquired from four orthodontic patients aged 14-18 years (two males and two females) at the Hospital of Stomatology, Sun Yat-sen University from September 2016 to October 2016. Teeth extracted for orthodontic treatment were included in the present study. Teeth with cavities, periodontitis, broken sputum or not fully developed apical foramens were excluded. As previously described (23), hPDLSCs were isolated from the periodontal ligament of the teeth, and cultured at $37^{\circ} \mathrm{C}$ with a limited dilution method in complete culture medium, containing $\alpha$ modified eagle medium (MEM; Gibco; Thermo Fisher Scientific, Inc.), 10\% fetal bovine serum, $100 \mathrm{U} / \mathrm{ml}$ penicillin and $100 \mu \mathrm{g} / \mathrm{ml}$ streptomycin (all Gibco; Thermo Fisher Scientific, Inc.). The osteogenic and adipogenic differentiation potential of the hPDLSCs was investigated by alizarin red S staining and oil red $\mathrm{O}$ staining, respectively. After 1 day of culture, hPDLSCs were cultured with osteoblast-inducing medium $(0.1 \mu \mathrm{M}$ dexamethasone, $50 \mu \mathrm{g} / \mathrm{ml}$ ascorbic acid and $10 \mathrm{mM} \beta$-glycerol phosphate) or adipogenic medium (100 nM dexamethasone, $10 \mu \mathrm{g} / \mathrm{ml}$ insulin, $0.5 \mathrm{mM} 3$-isobutyl-1-methylxanthine and $50 \mathrm{mM}$ indomethacin). After 2 weeks, adipogenic induced cells were fixed in $4 \%$ paraformaldehyde for $15 \mathrm{~min}$ at room temperature and stained with Oil Red $\mathrm{O}$ staining solution (Nanjing Jiancheng Bioengineering Institute, Nanjing, China) at room temperature, according to the manufacturer's protocol. Briefly, cells were stained with reagent 1 for $15 \mathrm{~min}$, washed with distilled water for $20 \mathrm{sec}$ and subsequently stained with reagent 2 for $5 \mathrm{~min}$. Furthermore, after 4 weeks, the osteoblast induced cells were fixed in $4 \%$ paraformaldehyde and stained with Alizarin Red S staining solution (Sigma-Aldrich; Merck KGaA) for 3 min at room temperature. All dishes were subsequently dried at room temperature and observed under an optical light microscope at x200 magnification.

The colony-forming ability was assessed using colonyforming assays as previously described (23). Briefly, human PDLSCs (P3) were seeded in $10 \mathrm{~cm}$ diameter culture dishes at a density of $1 \times 10^{3}$ cells per dish and cultured in complete medium. After 12 days of incubation, cells were fixed in $4 \%$ paraformaldehyde for $15 \mathrm{~min}$ at room temperature and stained with $0.1 \%$ crystal violet (Sigma-Aldrich; Merck KGaA) for $15 \mathrm{~min}$ at room temperature. The dishes were subsequently washed twice with PBS and observed under an inverted microscope at x30 magnification. An aggregate of 50 or more cells were considered colony unit and were included in the final statistical analysis; aggregates of fewer cells were excluded. Cloning formation efficiency was assessed by examining the ratio of colony units and seeding cell number.

The specific surface markers of hPDLSCs, including integrin $\beta-1$ [cluster of differentiation (CD)29], cell surface glycoprotein MUC18 (CD146), CD44 (antigen CD44), thy-1 membrane glycoprotein (CD90), hematopoietic progenitor cell antigen (CD34) and receptor-type tyrosine-protein phosphatase C (CD45) were identified by flow cytometry. 
Table I. Primer nucleotide sequences for the reverse transcription-quantitative polymerase chain reaction.

\begin{tabular}{|c|c|}
\hline Gene & Primer nucleotide sequence \\
\hline \multirow[t]{2}{*}{$\beta$-actin } & Forward: 5'-GCCTTCAAGGTGGTAGCCC-3' \\
\hline & Reverse: 5'-CGTTACCCGCCATGACAGTA-3' \\
\hline \multirow[t]{2}{*}{ ALP } & Forward: 5'-CATGAAATACGAGATCCACCGAGAC-3' \\
\hline & Reverse: 5'-ATGCGACCACCCTCCACGAAG-3' \\
\hline \multirow[t]{2}{*}{$\mathrm{OCN}$} & Forward: 5'-CCCAGGCGCTACCTGTATCAA-3' \\
\hline & Reverse: 5'-GGTCAGCCAACTCGTCACAGTC-3' \\
\hline \multirow[t]{2}{*}{ RUNX2 } & Forward: 5'-TGGTTACTGTCATGGCGGGTA-3' \\
\hline & Reverse: 5'-TCTCAGATCGTTGAACCTTGCTA-3' \\
\hline
\end{tabular}

ALP, alkaline phosphatase; OCN, osteocalcin; RUNX2, runt-related transcription factor 2.

Briefly, once $90 \%$ confluence was reached, hPDLSCs were trypsinized and incubated with all antibodies diluted at 1:100, CD146 (cat. no. sc-53369), CD29 (cat. no. sc-59827), CD44 (cat. no. sc-65265), CD90 (cat. no. sc-53116), CD34 (cat. no. sc-133082) and CD45 (cat. no. sc-53045) at $4^{\circ} \mathrm{C}$ for $16 \mathrm{~h}$ in the dark, all of which were mouse $\mathrm{IgG}$-flourescein isothiocyanate (FITC) antibodies purchased from Santa Cruz Biotechnology, Inc. (Dallas, TX, USA). Cell suspensions incubated with served as controls. Finally, cells were fixed with $4 \%$ paraformaldehyde for $15 \mathrm{~min}$ at room temperature, washed three times with PBS and analyzed via fluorescence-activated cell sorting with a flow cytometer (BD Biosciences, San Jose, CA, USA) and BD Cell Quest Pro software (version 5.1; BD Biosciences). Cells passaged to $\mathrm{P} 4$ were used in the following experiments.

Cell seeding. Prior to seeding hPDLSCs, the scaffolds were immersed in $70 \%$ ethanol for $12 \mathrm{~h}$, air-dried in a clean workstation for 1 day and incubated with $\alpha$-MEM in 24-well plates for 7 days. Subsequently, hPDLSCs were seeded on the scaffolds at a density of $1 \times 10^{6}$ cells/well.

Cell adhesion. Following 1 and 2 days of culture, the adherent cells were fixed in $3 \%$ paraformaldehyde for $15 \mathrm{~min}$ and stained with DAPI (Beyotime Institute of Biotechnology, Shanghai, China) for $10 \mathrm{~min}$ at room temperature. The cell numbers on each scaffold were counted in five random fields, under an epifluorescence microscope (Observer.Z1; Zeiss GmbH) at x50 magnification.

Cell proliferation. Following culturing for 1, 3, 5, and 7 days, the cell proliferation of hPDLSCs was assessed using a Cell Counting Kit (CCK)-8 assay (Beyotime Institute of Biotechnology). At each time point, medium was replaced with serum-free medium containing CCK- 8 solution $(0.5 \mathrm{mg} / \mathrm{ml})$ at $37^{\circ} \mathrm{C}$ under $5 \% \mathrm{CO}_{2}$ for $2 \mathrm{~h}$. The optical density (OD) at $450 \mathrm{~nm}$ was measured using a spectrophotometer (Dojindo Molecular Technologies, Inc., Kumamoto, Japan).

Cell morphology. Following 3 days of incubation, the cell morphology of the hPDLSCs was observed under SEM. The samples were fixed in $2.5 \%$ (w/w) glutaraldehyde for $4 \mathrm{~h}$ at $4^{\circ} \mathrm{C}$, dehydrated in a $30,50,70,90$ and $100 \%$ ethanol series
(15 min for each step), freeze-dried and sputter coated with gold for SEM observation.

Cell adhesion morphology. Following culturing for 7 and 14 days, the cytoskeletal morphology of the hPDLSCs was observed using confocal laser scanning microscopy (CLSM: LSM780; Zeiss $\mathrm{GmbH}$ ) at a magnification of x50 and x200, and SEM at a magnification of x75 and x1,000. Samples for CLSM observation were fixed in $3 \%$ paraformaldehyde for $10 \mathrm{~min}$ at room temperature, and immersed in $0.1 \%$ TritonX-100 for $10 \mathrm{~min}$. The cells were subsequently stained with 1:100 Actin-Tracker Green (Beyotime Institute of Biotechnology) and DAPI at $37^{\circ} \mathrm{C}$ for $1 \mathrm{~h}$. Samples for SEM observation were prepared by the same protocol as for cell morphology observation.

Alizarin Red S staining. Subsequent to 14 days of osteogenic induction, the hPDLSCs on scaffolds were fixed in 3\% paraformaldehyde for $10 \mathrm{~min}$, and stained with Alizarin Red S staining solution (Beyotime Institute of Biotechnology) for $1 \mathrm{~min}$, both at room temperature. The scaffolds were subsequently washed twice with PBS until no more color appeared and observed under an optical microscope at x30 magnification. Finally, 2\% cetylpyridinium chloride was added to the samples to dissolve the mineralized nodules. The OD at $562 \mathrm{~nm}$ was measured using a spectrophotometer.

Alkaline phosphatase (ALP) activity. Subsequent to seeding for 1 day, the hPDLSCs were cultured with osteoblast-inducing medium containing $0.1 \mu \mathrm{M}$ dexamethasone, $50 \mu \mathrm{g} / \mathrm{ml}$ ascorbic acid and $10 \mathrm{mM} \beta$-glycerol phosphate. On day 7 and 14, protein concentration and ALP activity were determined using a bicinchoninic acid protein assay kit (Beijing ComWin Biotech Co., Ltd., Beijing, China) and an ALP kit (Nanjing Jiancheng Bioengineering Institute), respectively, according to the manufacturer's protocols. OD values were measured at 560 and $520 \mathrm{~nm}$, correspondingly, using a spectrophotometer. ALP activity was normalized to the total protein amount.

Expression of osteogenic biomarkers. hPDLSCs were cultured with osteoblast-inducing medium for 7 and 14 days. Total RNA was extracted from hPDLSCs using the RNAzol RNA extraction reagent (GeneCopoeia, Inc., Rockville, MD, USA; 

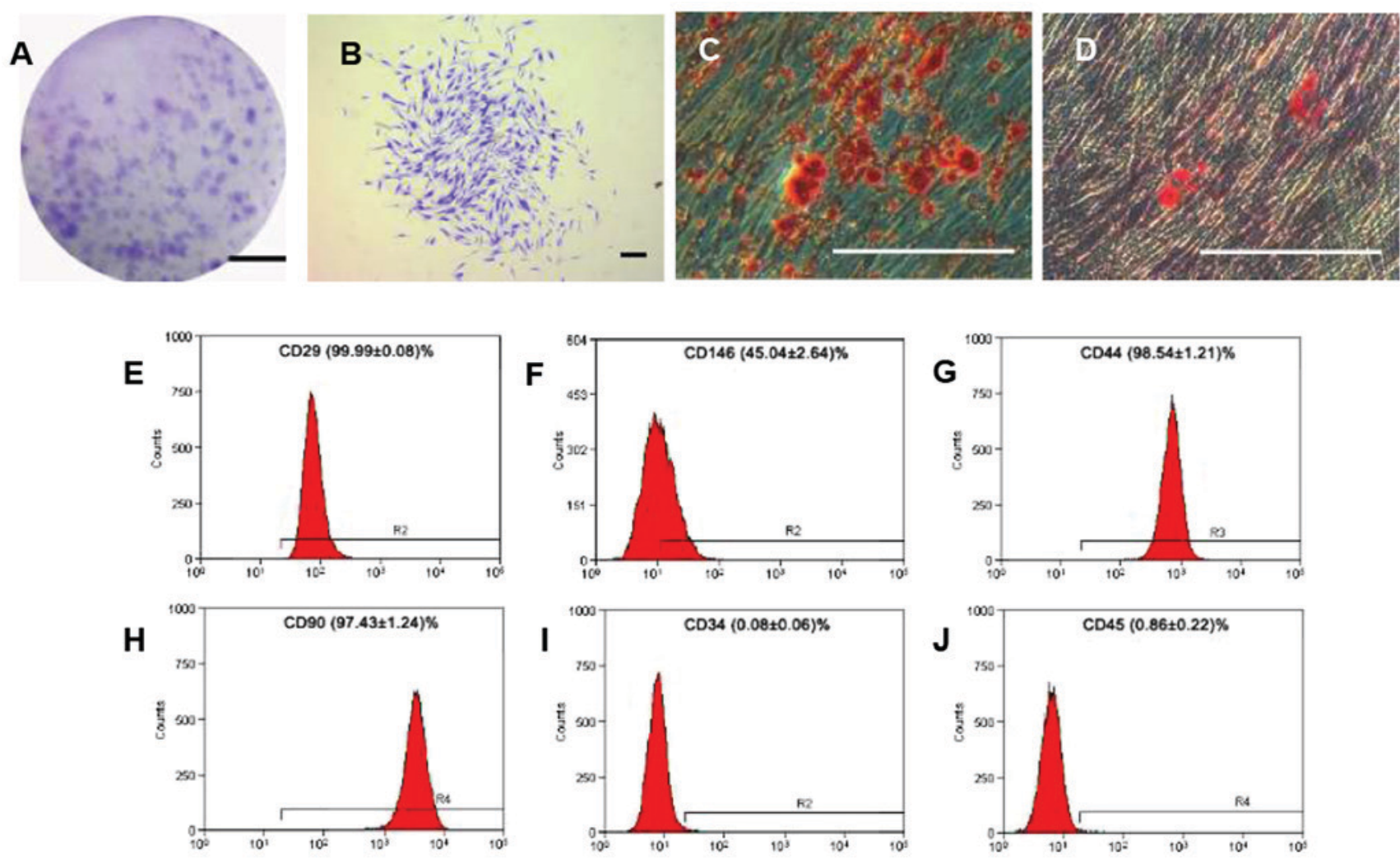

Figure 1. Cell culture and identification of hPDLSCs. (A) Colony forming units of hPDLSCs after cultivation for 12 days. Scale bar, $2 \mathrm{~cm}$ (B) Single clone of hPDLSCs. (C) Mineralized nodules identified by alizarin red S staining following osteogenic induction for 28 days. (D) Oil red O-positive lipid clusters identified following adipogenic induction for 14 days. (B-D) Scale bar, $300 \mu \mathrm{m}$. Flow cytometric analyses for surface markers of hPDLSCs: (E) CD29; (F) CD146; (G) CD44; (H) CD90; (I) CD34; and (J) CD45. hPDLSCs, human periodontal ligament stem cells; CD, cluster of differentiation; CD29, integrin $\beta-1$; CD146, cell surface glycoprotein, CD44, antigen CD44; CD90, thy-1 membrane glycoprotein; CD34, hematopoietic progenitor cell antigen; CD45, receptor-type tyrosine-protein phosphatase $\mathrm{C}$.

cat. no. RN190). The reverse transcription (RT) reactions were performed using Prime Script RT Master Mix (cat. no. RR037; Takara Bio, Inc., Otsu, Japan). The RT was performed at $37^{\circ} \mathrm{C}$ for $15 \mathrm{~min}$ and $85^{\circ} \mathrm{C}$ for $5 \mathrm{sec}$. A quantitative polymerase chain reaction (qPCR) was conducted using a SYBR PCR Master Mix kit (cat. no. 4367218; Thermo Fisher Scientific, Inc.) and $10 \mu \mathrm{M}$ specific primers in $20 \mu \mathrm{l}$, consisting of 40 cycles at $95^{\circ} \mathrm{C}$ for $10 \mathrm{~min}, 95^{\circ} \mathrm{C}$ for $15 \mathrm{sec}, 60^{\circ} \mathrm{C}$ for $60 \mathrm{sec}$, and $72^{\circ} \mathrm{C}$ for $30 \mathrm{sec}$. The data were acquired using the LightCycler480 System (Bio-Rad Laboratories, Inc., Hercules, CA, USA). $\beta$-actin was used to normalize the expression level of ALP, osteocalcin (OCN) and runt-related transcription factor 2 (RUNX2). The primers are presented in Table I. Relative expression was calculated using the $2^{-\Delta \Delta \mathrm{Cq}}$ method (24).

Statistical analysis. Data are presented as the mean \pm standard deviation $(\mathrm{n}=5)$ and were statistically analyzed using SPSS 13.0 (SPSS, Inc., Chicago, IL, USA). The difference among groups was analyzed by one-way analysis of variance followed by the Student-Newman-Keuls post hoc test. $\mathrm{P}<0.05$ was considered to indicate a statistically significant difference.

\section{Results}

hPDLSC culture and identification. Colony-forming units of the hPDLSCs were counted and the colony formation efficiency was $30.2 \%$ (Fig. 1A and B). The hPDLSCs displayed long spindle morphology, and demonstrated the ability for osteogenic (Fig. 1C) and adipogenic differentiation (Fig. 1D). The flow cytometric analyses demonstrated that the hPDLSCs were positive for CD29 (adhesion molecule), CD146 (mesenchymal stem cell marker), CD44 (receptor molecule) and CD90 (extracellular matrix protein); however, they were negative for CD34 and CD45 (hematopoietic and angiogenic lineage markers) (Fig. 1E-J).

Surface characteristics (morphology, surface roughness and wettability). As demonstrated in Fig. 2A, the surface of the 0.9PCL/0.1PLGA scaffold was rough and exhibited micro-sized pores. By comparison, the surfaces of the 0.1PCL/0.9PLGA and 0.5PCL/0.5PLGA scaffold were smooth.

Surface roughness is exhibited in Fig. $2 \mathrm{~B}$ and $\mathrm{C}$. The introduction of PLGA into PCL decreased the Sa and Sq. The Sa value of 0.9PCL/0.1PLGA was significantly higher compared with the other two groups $(\mathrm{P}<0.01)$. Sq values shared the same tendency as Sa (Fig. 2C).

Water contact angle images are illustrated in Fig. 2D. The water angle of the composites decreased and the surface hydrophilicity increased with the increasing proportion of PLGA. The average values of the CAs of $0.1 \mathrm{PCL} / 0.9 \mathrm{PLGA}\left(86.60 \pm 3.60^{\circ}\right)$ and $0.5 \mathrm{PCL} / 0.5 \mathrm{PLGA}\left(94.93 \pm 4.14^{\circ}\right)$ were significantly lower compared with 0.9PCL/0.1PLGA $\left(133.83 \pm 6.53^{\circ}\right)(\mathrm{P}<0.01$; Table II). There was no significant difference observed between the two lower groups. 

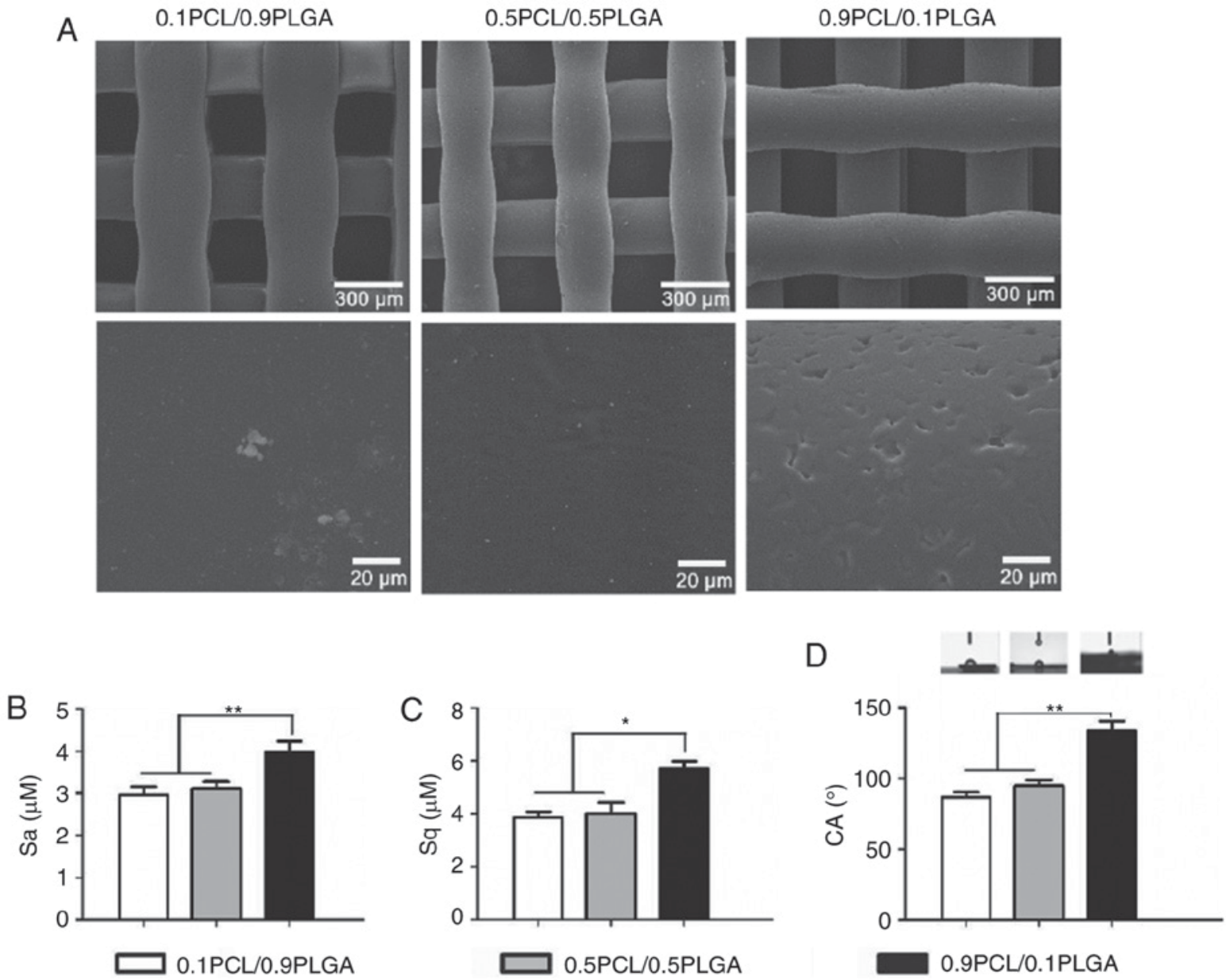

Figure 2. Surface characteristics of the PCL/PLGA scaffolds. (A) Scanning electron microscopy images of the 0.1PCL/0.9PLGA, 0.5PCL/0.5PLGA and 0.9PCL/0.1PLGA scaffolds. (B) Sa values of the three scaffolds. (C) Sq values of the three scaffolds. (D) CAs of the three scaffolds. ${ }^{*} \mathrm{P}<0.05,{ }^{* *} \mathrm{P}<0.01 . \mathrm{PCL}$, poly ( $\varepsilon$-caprolactone); PLGA, poly-lactic-co-glycolic acid; Sa, arithmetic average of the 3D roughness; Sq, quadratic average of the 3D roughness; CA, contact angle.

Table II. Surface roughness and hydrophilicity of the tested scaffolds $(n=5)$.

\begin{tabular}{lccc}
\hline Group & $\mathrm{Sa}, \mu \mathrm{m}$ & $\mathrm{Sq}, \mu \mathrm{m}$ & $\mathrm{CA},{ }^{\circ}$ \\
\hline $0.1 \mathrm{PCL} / 0.9 P L G A$ & $2.97 \pm 0.19^{\mathrm{c}}$ & $3.85 \pm 0.12^{\mathrm{c}}$ & $86.60 \pm 3.60^{\mathrm{c}}$ \\
0.5PCL/0.5PLGA & $3.12 \pm 0.06^{\mathrm{c}}$ & $4.01 \pm 0.42^{\mathrm{c}}$ & $94.93 \pm 4.14^{\mathrm{c}}$ \\
0.9PCL/0.1PLGA & $3.99 \pm 0.04^{\mathrm{a}, \mathrm{b}}$ & $5.70 \pm 0.68^{\mathrm{a}, \mathrm{b}}$ & $133.83 \pm 6.53^{\mathrm{a}, \mathrm{b}}$ \\
\hline
\end{tabular}

${ }^{\mathrm{a} P}<0.05$ vs. $0.1 \mathrm{PCL} / 0.1 \mathrm{PLGA},{ }^{\mathrm{b}} \mathrm{P}<0.05$ vs. $0.5 \mathrm{PCL} / 0.5 \mathrm{PLGA},{ }^{\mathrm{c}} \mathrm{P}<0.05$ vs.0.9PCL/0.1PLGA.PCL, poly ( $\varepsilon$-caprolactone); PLGA, poly-lacticco-glycolic acid; $\mathrm{Sa}$, arithmetic average of the 3D roughness; $\mathrm{Sq}$, quadratic average of the $3 \mathrm{D}$ roughness; $\mathrm{CA}$, contact angle.

Degradation properties/alterations in mass and $\mathrm{pH}$. As demonstrated in Fig. 3A, PLGA addition may adjust the degradation rates of PCL/PLGA scaffolds. The presence of PLGA significantly accelerated the mass loss of the composites. Following 12 weeks, the mass loss was $79.20 \pm 4.22,51.89 \pm 4.56$ and $10.21 \pm 2.16 \%$ for the $0.1 \mathrm{PCL} / 0.9 \mathrm{PLGA}, 0.5 \mathrm{PCL} / 0.5 \mathrm{PLGA}$ and $0.9 \mathrm{PCL} / 0.1 \mathrm{PLGA}$ scaffolds, respectively.

Overall, the $\mathrm{pH}$ values of the composites decreased with the increasing ratio of PLGA at each time point
(Fig. 3B). At 6 weeks of degradation, the $\mathrm{pH}$ values of the three different scaffolds reached the minimum, which was $6.67 \pm 0.02,7.01 \pm 0.06$ and $7.12 \pm 0.02$ for $0.1 \mathrm{PCL} / 0.9 \mathrm{PLGA}$, $0.5 \mathrm{PCL} / 0.5 \mathrm{PLGA}$ and $0.9 \mathrm{PCL} / 0.1 \mathrm{PLGA}$, respectively. Additionally, a significant difference was observed in the $\mathrm{pH}$ values between 0.1PCL/0.9PLGA and the other two scaffolds following $3(\mathrm{P}<0.05)$ and 6 weeks $(\mathrm{P}<0.01)$ of degradation, and between 0.1PCL/0.9PLGA and 0.9PCL/0.1PLGA at 9 weeks of degradation $(\mathrm{P}<0.05)$.

Cell adhesion. As demonstrated in Fig. 4A, the initial adherent number of hPDLSCs on 0.1PCL/0.9PLGA and 0.5PCL/0.5PLGA was significantly higher compared with $0.9 \mathrm{PCL} / 0.1 \mathrm{PLGA}$ on day $1(\mathrm{P}<0.05)$ and day $2(\mathrm{P}<0.01)$. No significant difference between 0.1PCL/0.9PLGA and 0.5 PCL/0.5PLGA was revealed on day 2 .

Cell proliferation. As presented in Fig. 4B, the proliferation of the hPDLSCs on different scaffolds demonstrated a specific order at each time point with the exception of day 1 , with the ranking $0.5 \mathrm{PCL} / 0.5 \mathrm{PLGA}>0.9 \mathrm{PCL} / 0.1 \mathrm{PLGA}$ $>0.1$ PCL/0.9PLGA. On day 1 and day 3 , no significant difference was observed among the groups $(\mathrm{P}>0.05)$. On day 5 and day 7, the proliferation level was significantly higher in $0.5 \mathrm{PCL} / 0.5 \mathrm{PLGA}\left(\mathrm{OD}_{5 \mathrm{~d}}=2.03 \pm 0.05 ; \mathrm{OD}_{7 \mathrm{~d}}=2.33 \pm 0.13\right)$ and 
A

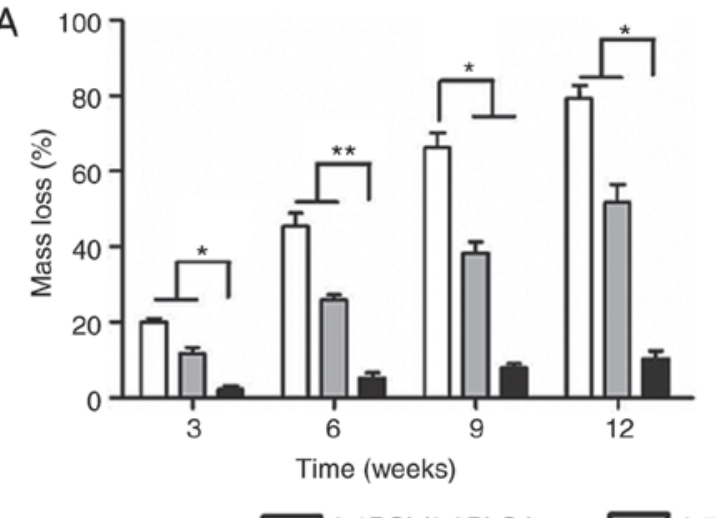

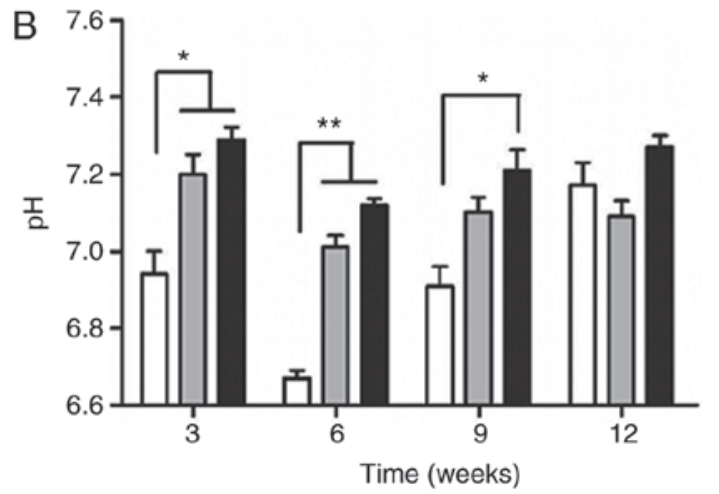

0.5PCL/0.5PLGA

$0.9 P C L / 0.1 P L G A$

Figure 3. Degradation properties of PCL/PLGA scaffolds. (A) Mass loss and (B) $\mathrm{pH}$ value of the tested scaffolds during degradation in PBS (initial pH of 7.4). ${ }^{*} \mathrm{P}<0.05,{ }^{* *} \mathrm{P}<0.01$. PCL, poly ( $\varepsilon$-caprolactone); PLGA, poly-lactic-co-glycolic acid.
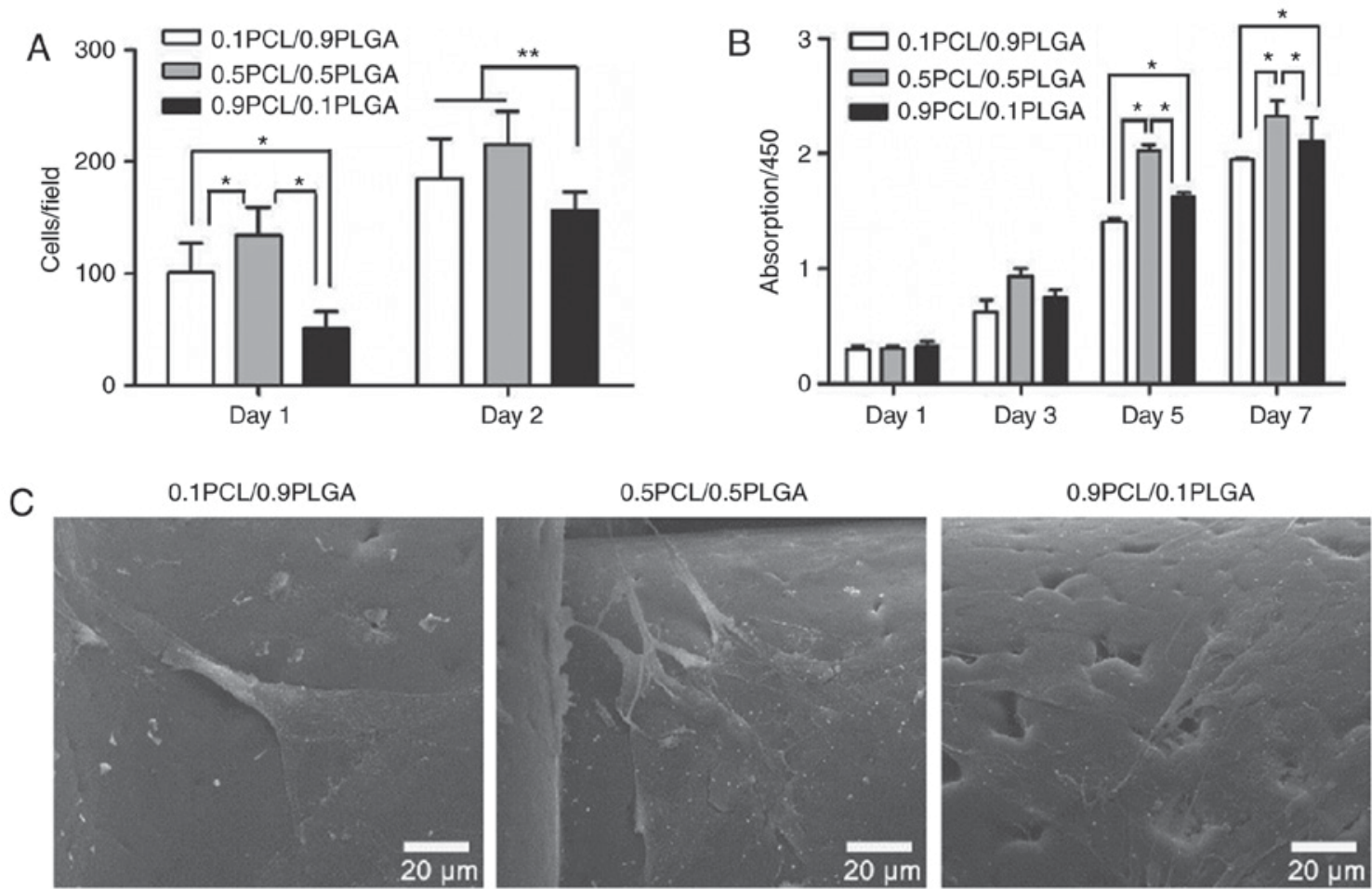

Figure 4. Adhesion, proliferation and morphology of hPDLSCs on the PCL/PLGA scaffolds. (A) Cell adhesion rates of the 0.1PCL/0.9PLGA, 0.5PCL/0.5PLGA and 0.9PCL/0.1PLGA scaffolds at 1 and 2 days post-seeding. (B) Cell proliferation on the scaffolds following 7 days. (C) Scanning electron microscopy images of hPDLSCs cultured on the scaffolds following 3 days. ${ }^{*} \mathrm{P}<0.05,{ }^{* *} \mathrm{P}<0.01$. hPDLSCs, human periodontal ligament stem cells; PCL, poly ( $\varepsilon$-caprolactone); PLGA, poly-lactic-co-glycolic acid.

significantly lower in $0.1 \mathrm{PCL} / 0.9 \mathrm{PLGA}\left(\mathrm{OD}_{5 \mathrm{~d}}=1.62 \pm 0.04\right.$; $\left.\mathrm{OD}_{7 \mathrm{~d}}=2.11 \pm 0.20\right)$ compared with $0.9 \mathrm{PCL} / 0.1 \mathrm{PLGA}$ $\left(\mathrm{OD}_{5 \mathrm{~d}}=1.41 \pm 0.03 ; \mathrm{OD}_{7 \mathrm{~d}}=1.95 \pm 0.01\right)(\mathrm{P}<0.05)$.

Cell morphology. The morphology of the hPDLSCs was demonstrated in Fig. 4C following 3 days of culture. Cells on 0.5 PCL/0.5PLGA were highly branched, polygonal shaped and exhibited clear nuclei; whereas, cells were flat on the 0.1PCL/0.9PLGA scaffold, and spindle-like with fewer branch points on the 0.9PCL/0.1PLGA scaffold.

Cell adhesion morphology. The cell adhesion morphology of the hPDLSCs was observed following 7 and 14 days of incubation on the scaffolds (Fig. 5). SEM and CLSM images at low magnification demonstrated that with culture time, hPDLSCs gradually grew on the scaffold surface and formed cell layers. Subsequent to 14 days of culture, hPDLSCs grew on the struts and additionally over the porous structure of the 0.1PCL/0.9PLGA and 0.5PCL/0.5PLGA scaffolds (yellow arrows); whereas, hPDLSCs only covered the struts and not the porous structure of the 0.9PCL/0.1PLGA scaffolds.

SEM images at high magnification revealed that hPDLSCs were well adhered to the surfaces of all scaffolds. The hPDLSCs formed denser cell layers on the 0.5PCL/0.5PLGA scaffolds compared with on the 0.1PCL/0.9PLGA and 0.9PCL/0.1PLGA scaffolds. CLSM images at high magnification revealed that 
Day 7

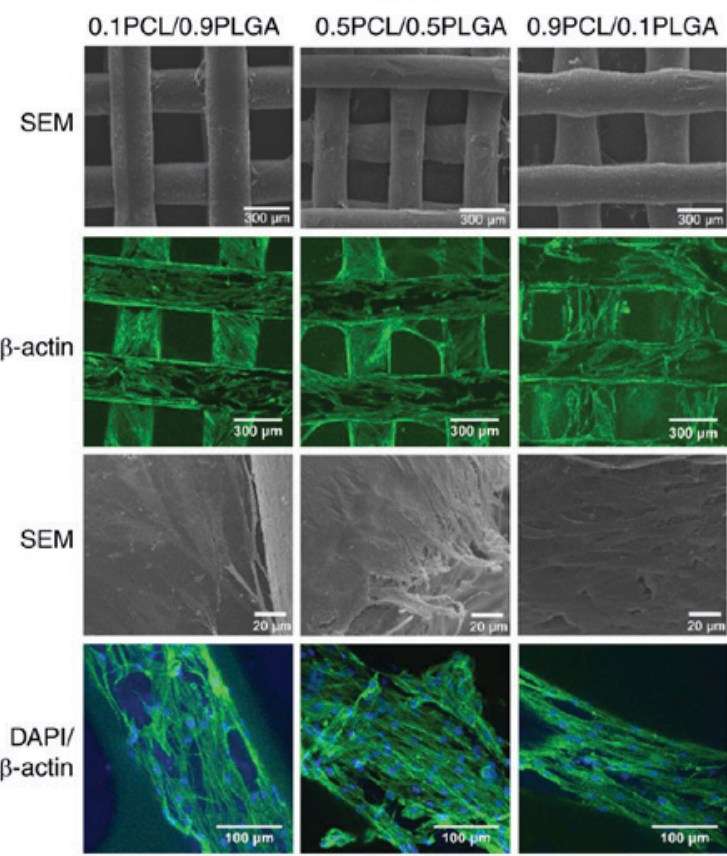

Day 14
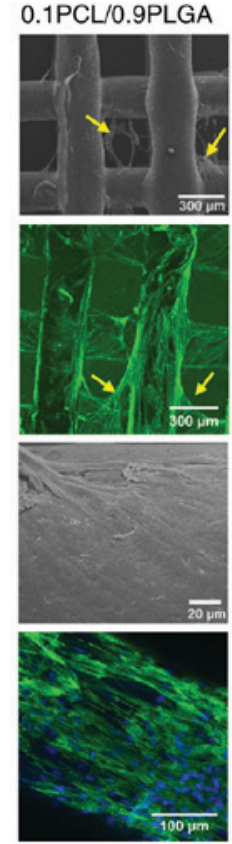

.5PCL/0.5PLGA $0.9 P C L / 0.1 P L G A$
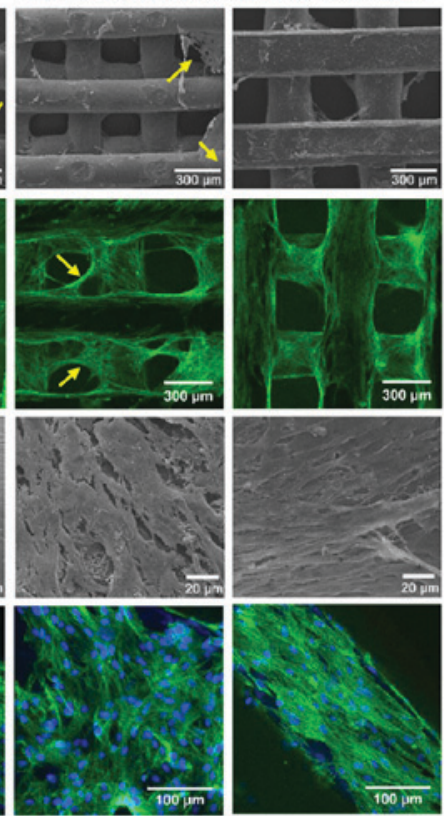

Figure 5. Confocal laser scanning microscropy and SEM images of hPDLSCs on the PCL/PLGA scaffolds on day 7 and day 14 . Immunofluorescence staining with filamentous actin (green) and DAPI (blue) for seeded cells on the scaffolds. SEM, scanning electron microscope; hPDLSCs, human periodontal ligament stem cells; PCL, poly ( $\varepsilon$-caprolactone); PLGA, poly-lactic-co-glycolic acid.
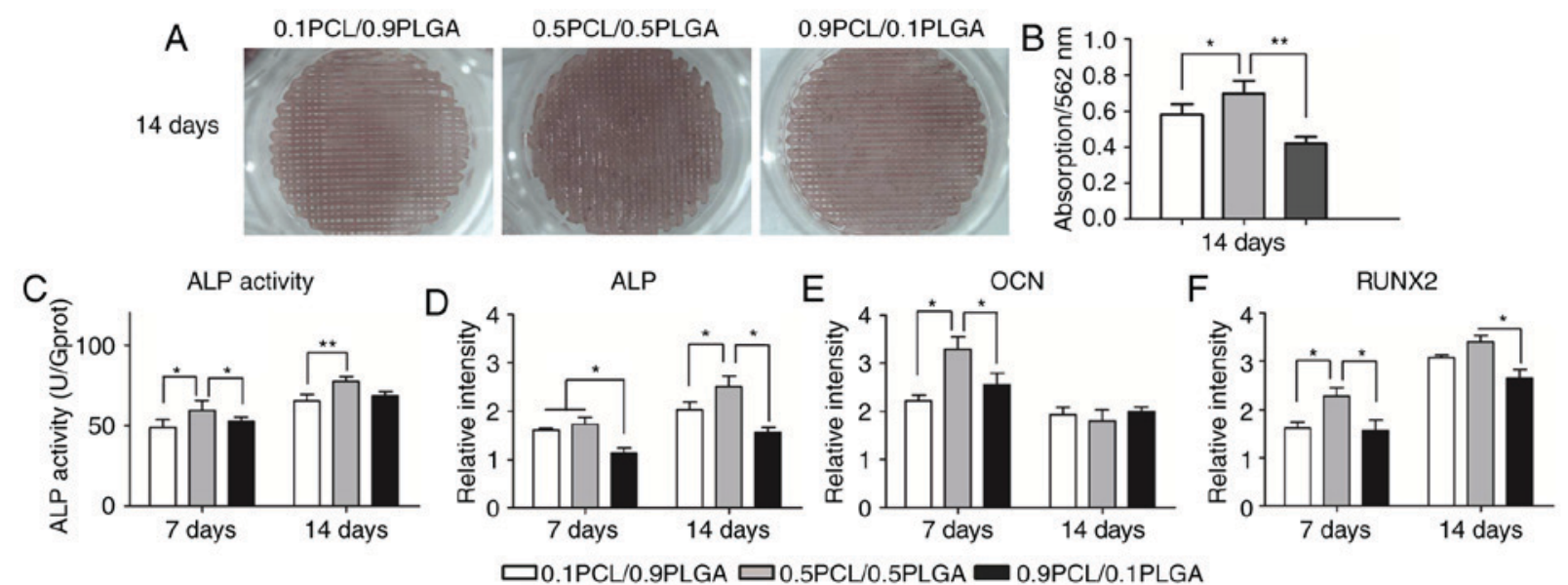

Figure 6. Osteogenic capacity of hPDLSCs on PCL/PLGA scaffolds. Optical microscopy of (A) Alizarin Red S staining and (B) semi-quantification of hPDLSCs seeded on the scaffolds. (C) ALP activity of hPDLSCs seeded on the scaffolds. Reverse transcription-quantitative polymerase chain reaction detection of (D) ALP, (E) OCN and (F) RUNX2 of hPDLSCs seeded on the scaffolds. ${ }^{*} \mathrm{P}<0.05,{ }^{* *} \mathrm{P}<0.01$. hPDLSCs, human periodontal ligament stem cells; PLGA, poly-lactic-co-glycolic acid. PCL, poly ( $\varepsilon$-caprolactone); PLGA, poly-lactic-co-glycolic acid; ALP, alkaline phosphatase; OCN, osteocalcin; RUNX2, runt-related transcription factor 2; GProt grams of protein.

abundant stress fibers and actin microfilaments were observed on the 0.5PCL/0.5PLGA scaffolds with fewer cellular junctions revealed on the $0.1 \mathrm{PCL} / 0.9 \mathrm{PLGA}$ and $0.9 \mathrm{PCL} / 0.1 \mathrm{PLGA}$ scaffolds.

Osteogenic differentiation. Extracellular matrix mineralization of hPDLSCs on scaffolds following 14 days of osteogenic induction is demonstrated in Fig. 6A. Markedly dense red color in the struts of the $0.5 \mathrm{PCL} / 0.5 \mathrm{PLGA}$ scaffolds was observed, with pale red color on the 0.1PCL/0.9PLGA and 0.9PCL/0.1PLGA scaffolds. The semi-quantitative analysis (Fig. 6B) demonstrated that hPDLSCs cultured on the
0.5PCL/0.5PLGA $\left(\mathrm{OD}_{562}=0.70 \pm 0.07\right)$ scaffolds produced a higher level of deposited calcium compared with the 0.1PCL/0.9PLGA $\left(\mathrm{OD}_{562}=0.58 \pm 0.06\right)$ and 0.9PCL/0.1PLGA $\left(\mathrm{OD}_{562}=0.42 \pm 0.04\right)$ scaffolds $(\mathrm{P}<0.05)$.

ALP activity was determined to assess the early osteogenic capacity of the hPDLSCs on the scaffolds (Fig. 6C). The overall ALP activity of the hPDLSCs on the 0.5PCL/0.5PLGA surface was significantly higher compared with the other two groups on day 7 and day $14(\mathrm{P}<0.05)$, apart from no significant difference compared with 0.1PCL/0.9PLGA on day 14.

The expression of osteogenic biomarkers of hPDLSCs on scaffolds was detected using a qPCR (Fig. 6D-F). Overall, 
the mRNA expression of ALP and RUNX2 was higher on day 14 compared with on day 7, while the expression of OCN mRNA demonstrated the opposite trend. Following culturing for 7 days, the OCN and RUNX2 mRNA expression of the cells grown on the $0.5 \mathrm{PCL} / 0.5 \mathrm{PLGA}$ scaffolds was significantly higher compared with the other two groups $(\mathrm{P}<0.05)$. Additionally, the expression level of ALP mRNA was significantly higher in the 0.1PCL/0.9PLGA and 0.5PCL/0.5PLGA groups compared with the 0.9PCL/0.1PLGA group $(\mathrm{P}<0.05)$. Subsequent to 14 days of culture, the mRNA expression of ALP and RUNX2 were the highest, and the difference between the 0.5PCL/0.5PLGA scaffolds and the 0.9PCL/0.1PLGA scaffolds was statistically significant $(\mathrm{P}<0.05)$.

\section{Discussion}

In the present study, PCL/PLGA blended scaffolds with highly porous interconnected networks were successfully created using the FDM technique. The topological structure of the scaffolds directly affects cell activity and tissue regeneration (25). Karageorgiou and Kaplan (26) reported that a scaffold with $300-500 \mu \mathrm{m}$ pores optimized vascularization, and enhanced cell adhesion and new tissue integration. Levenberg et al (27) suggested that the size of the struts should not exceed $400 \mu \mathrm{m}$ in any dimension; otherwise, it may inhibit the $\mathrm{O}_{2}$ diffusion and result in local tissue hypoxia and necrosis. The pore diameter and the cross-section of the beam and column of the scaffolds in the present study was $300 \mu \mathrm{m}$, suitable for bone regeneration.

Scaffolds should break down at a rate that is harmonious with the rate of cell growth and tissue maturation (28). The degradation rate of the PCL/PLGA scaffolds was adjustable by altering the concentration of PLGA. The 0.5PCL/0.5PLGA composite scaffold demonstrated an ideal degradation rate; the degradation of the 0.1PCL/0.9PLGA scaffold was too fast and the 0.9PCL/0.1PLGA scaffold was too slow. PLGA is hydrophilic, and hence is able to accelerate the hydrolytic degradation of hybrid PCL/PLGA (29). However, PLGA had acidic byproducts during degradation, which may consequently inhibit cell viability and induce tissue inflammation (30). It was revealed in the present study that with the proportion of PLGA decreasing, the scaffolds exhibited fewer acidic byproducts, demonstrating their potential use in biomedical applications.

Biomaterials are required to allow cell attachment, which is termed biocompatibility (31). Following cell attachment and proliferation, the material should break down and be replaced by the extracellular matrix $(32,33)$. A previous study indicated that hybrid PCL/PLGA may facilitate the adhesion and proliferation of stem cells (34). The present data demonstrated that hPDLSCs on the 0.5PCL/0.5PLGA and 0.1PCL/0.9PLGA scaffolds had a significantly higher rate of attachment and proliferation compared with the 0.9PCL/0.1PLGA scaffolds. Furthermore, hPDLSCs on 0.5PCL/0.5PLGA presented a uniform appearance resembling mesenchymal stem cells and exhibited enhanced cell bridging following 7 and 14 days of seeding. The differences may be due to the different roughness and hydrophilicity of the scaffolds (35).

Additionally, 0.5PCL/0.5PLGA demonstrated a superior osteogenic capacity compared with the other two scaffolds, confirmed with higher ALP activity and higher expression of bone-related markers, including ALP, OCN and RUNX2, consistent with a previous study reported by Makadia and Siegel (29), who discovered that a PCL/PLGA composite may induce differentiation of osteoblasts. The promotion of osteogenic capacity may be due to improved early cell attachment and proliferation on the 0.5PCL/0.5PLGA scaffold. Cell morphology may be another reason for osteogenesis, as stretching of cells may affect intracellular communication and upregulate osteogenic gene expression $(36,37)$.

Biological behavior is associated with the surface characteristics of the scaffolds. Generally, scaffolds must possess adequate roughness, hydrophilicity and specific surface topography, which are widely accepted to affect cell attachment, proliferation and differentiation $(38,39)$. The present data revealed that the surface roughness of composite scaffolds increased with the increased proportion of PCL. Thapa et al (40) discovered a rougher surface of PCL compared with PLGA following dissolution and deposition. Other researchers reported that different surface topographies resulted from pores with various sizes $(5-40 \mathrm{~nm})$ formed on the polymer surface during the crystallization process following deposition (41), and the size of pores was strongly influenced by the polymer blend ratio (42).

Another study suggested that the increased surface roughness provides a larger surface area, and thus leads to increased cell adhesion (43). However, in the present study, early cell attachment and proliferation did not alter correspondingly with the increase in surface roughness. This result was in accordance with studies reported by Liao et al (44) and Deng et al (45). Therefore, superior hPDLSC responses on the PCL/PLGA scaffolds may be attained by modifying surface roughness with different ratios of PCL/PLGA.

Surface wettability was additionally responsible for the cell response on the material. Highly hydrophilic surfaces facilitate the initial attachment of water molecules, promoting the adsorption of proteins, including fibronectin (46). Furthermore, hydrophilic surfaces demonstrate high surface energies and enhanced cell adhesion $(47,48)$. It was observed that the hydrophilicity of PLGA/PCL hybrid scaffolds increased with the higher PLGA ratio, which was positively associated with cell attachment, viability and differentiation.

In summary, the present study demonstrated that PCL/PLGA composite scaffolds exhibited good degradation properties, surface characteristics and cellular activities, demonstrating potential in alveolar bone restoration, and 0.5PCL/0.5PLGA (w/w) possessed superior bioactivity. Further studies are required to examine the in vivo effect in animal models.

\section{Acknowledgements}

Not applicable.

\section{Funding}

This study was supported by the Natural Science Foundation of Guangdong Province (China; grant no. 2015A030313083).

\section{Availability of data and materials}

The data sets used and/or analyzed during the current study are available from the corresponding author on reasonable request. 


\section{Authors' contributions}

LW, JZ and CP conceived and designed the experiments. $\mathrm{XZ}, \mathrm{LD}$ and $\mathrm{CP}$ performed the experiments. CP, ZC and DC analyzed the data. CP drafted the manuscript. CP and LW critically revised the manuscript.

\section{Ethics approval and consent to participate}

The protocol was approved by the Ethics Committee of the Hospital of Stomatology, Sun Yat-sen University (Guangzhou, China; approval no. PKUSSIRB-201311103). Informed consent from each patient was obtained.

\section{Consent for publication}

Not applicable.

\section{Competing interests}

The authors declare that they have no competing interests.

\section{References}

1. Asa'ad F, Pagni G, Pilipchuk SP, Gianni AB, Giannobile WV and Rasperini G: 3D-printed scaffolds and biomaterials: Review of alveolar bone augmentation and periodontal regeneration applications. Int J Dent 2016: 1239842, 2016.

2. Teven CM, Fisher S, Ameer GA, He TC and Reid RR: Biomimetic approaches to complex craniofacial defects. Ann Maxillofac Surg 5: 4-13, 2015

3. Sheikh Z, Hamdan N, Ikeda Y, Grynpas M, Ganss B and Glogauer M: Natural graft tissues and synthetic biomaterials for periodontal and alveolar bone reconstructive applications: A review. Biomater Res 21: 9, 2017.

4. Obregon F, Vaquette C, Ivanovski S, Hutmacher DW and Bertassoni LE: Three-dimensional bioprinting for regenerative dentistry and craniofacial tissue engineering. J Dent Res 94 (9 Suppl): 143S-152S, 2015.

5. Hung BP, Naved BA, Nyberg EL, Dias M, Holmes CA, Elisseeff JH, Dorafshar AH and Grayson WL: Three-dimensional printing of bone extracellular matrix for craniofacial regeneration. ACS Biomater Sci Eng 2: 1806-1816, 2016.

6. Lu T, Li Y and Chen T: Techniques for fabrication and construction of three-dimensional scaffolds for tissue engineering. Int $\mathrm{J}$ Nanomedicine 8: 337-350, 2013.

7. Nyberg EL,Farris AL, Hung BP, Dias M, Garcia JR, Dorafshar AH and Grayson WL: 3D-printing technologies for craniofacial rehabilitation, reconstruction, and regeneration. Ann Biomed Eng 45 $45-57,2017$

8. Chia $\mathrm{HN}$ and Wu BM: Recent advances in $3 \mathrm{D}$ printing of biomaterials. J Biol Eng 9: 4, 2015.

9. Rasperini G, Pilipchuk SP, Flanagan CL, Park CH, Pagni G Hollister SJ and Giannobile WV: 3D-printed bioresorbable scaffold for periodontal repair. J Dent Res 942 (9 Supp): 153S-157S, 2015.

10. Chou SF and Woodrow KA: Relationships between mechanical properties and drug release from electrospun fibers of PCL and PLGA blends. J Mech Behav Biomed Mater 65: 724-733, 2017.

11. Li X, Yang C, Li L, Xiong J, Xie L, Yang B, Yu M, Feng L, Jiang Z, Guo W and Tian W: A therapeutic strategy for spinal cord defect: Human dental follicle cells combined with aligned PCL/PLGA electrospun material. Biomed Res Int 2015: 197183, 2015.

12. Jensen T, Blanchette A, Vadasz S, Dave A, Canfarotta M, Sayej WN and Finck C: Biomimetic and synthetic esophageal tissue engineering. Biomaterials 57: 133-141,2015.

13. Zong C, Wang M, Yang F, Chen G, Chen J, Tang Z, Liu Q, Gao C, Ma L and Wang J: A novel therapy strategy for bile duct repair using tissue engineering technique: PCL/PLGA bilayered scaffold with hMSCs. J Tissue Eng Regen Med 11: 966-976, 2017.

14. Trajano VCC, Costa KJR, Lanza CRM, Sinisterra RD and Cortes ME: Osteogenic activity of cyclodextrin-encapsulated doxycycline in a calcium phosphate PCL and PLGA composite. Mater Sci Eng C Mater Biol Appl 64: 370-375, 2016.
15. Franco RA, Nguyen TH and Lee BT: Preparation and characterization of electrospun PCL/PLGA membranes and chitosan/ gelatin hydrogels for skin bioengineering applications. J Mater Sci Mater Med 22: 2207-2218, 2011.

16. Baker SC, Rohman G, Southgate J and Cameron NR: The relationship between the mechanical properties and cell behaviour on PLGA and PCL scaffolds for bladder tissue engineering. Biomaterials 30: 1321-1328, 2009.

17. Subramanian A, Krishnan UM and Sethuraman S: Fabrication, characterization and in vitro evaluation of aligned PLGA-PCL nanofibers for neural regeneration. Ann Biomed Eng 40: 2098-2110, 2012.

18. Qian Y, Chen H, Xu Y, Yang J, Zhou X, Zhang F and Gu N: The preosteoblast response of electrospinning PLGA/PCL nanofibers: Effects of biomimetic architecture and collagen I. Int J Nanomedicine 11: 4157-4171, 2016.

19. Mrozik K, Gronthos S, Shi S and Bartold PM: A method to isolate, purify, and characterize human periodontal ligament stem cells. Methods Mol Biol 666: 269-284, 2010.

20. Zhu W and Liang M: Periodontal ligament stem cells: Current status, concerns, and future prospects. Stem Cells Int 2015: 972313, 2015

21. Cha Y, Jeon M, Lee HS, Kim S, Kim SO, Lee JH and Song JS: Effects of in vitro osteogenic induction on in vivo tissue regeneration by dental pulp and periodontal ligament stem cells. J Endod 41: 1462-1468, 2015.

22. Moshaverinia A, Xu X, Chen C, Ansari S, Zadeh HH, Snead ML and Shi S: Application of stem cells derived from the periodontal ligament or gingival tissue sources for tendon tissue regeneration. Biomaterials 35: 2642-2650, 2014

23. Zhang H, Liu S, Zhu B, Xu Q, Ding Y and Jin Y: Composite cell sheet for periodontal regeneration: Crosstalk between different types of MSCs in cell sheet facilitates complex periodontal-like tissue regeneration. Stem Cell Res Ther 7: 168, 2016

24. Livak KJ and Schmittgen TD: Analysis of relative gene expression data using real-time quantitative PCR and the 2(-Delta Delta C(T)) method. Methods 25: 402-408, 2001.

25. Bruzauskaite I, Bironaite D, Bagdonas E and Bernotiene E: Scaffolds and cells for tissue regeneration: Different scaffold pore sizes-different cell effects. Cytotechnology 68: 355-369, 2016.

26. Karageorgiou V and Kaplan D: Porosity of 3D biomaterial scaffolds and osteogenesis. Biomaterials 26: 5474-5491, 2005.

27. Levenberg S, Rouwkema J, Macdonald M, Garfein ES, Kohane DS, Darland DC, Marini R, van Blitterswijk CA, Mulligan RC, D'Amore PA and Langer R: Engineering vascularized skeletal muscle tissue. Nat Biotechnol 23: 879-884, 2005

28. Osorio R, Alfonso-Rodriguez CA, Osorio E, Medina-Castillo AL, Alaminos $\mathrm{M}$, Toledano-Osorio $\mathrm{M}$ and Toledano $\mathrm{M}$ : Novel potential scaffold for periodontal tissue engineering. Clin Oral Investig 21: 2695-2707, 2017

29. Makadia HK and Siegel SJ: Poly Lactic-co-glycolic acid (PLGA) as biodegradable controlled drug delivery carrier. Polymers (Basel) 3: 1377-1397, 2011.

30. Rhee SH and Lee SJ: Effect of acidic degradation products of poly(lactic-co-glycolic)acid on the apatite-forming ability of poly(lactic-co-glycolic)acid-siloxane nanohybrid material. J Biomed Mater Res A 83: 799-805, 2007.

31. Prakasam M, Locs J, Salma-Ancane K, Loca D, Largeteau A and Berzina-Cimdina L: Biodegradable materials and metallic Implants-a review. J Funct Biomater 8: pii: E44, 2017.

32. Pulyala P, Singh A, Dias-Netipanyj MF, Cogo SC, Santos LS, Soares P, Gopal V, Suganthan V, Manivasagam G and Popat KC: In-vitro cell adhesion and proliferation of adipose derived stem cell on hydroxyapatite composite surfaces. Mater Sci Eng C Mater Biol Appl 75: 1305-1316, 2017.

33. He HY, Zhang JY, Mi X, Hu Y and Gu XY: Rapid prototyping for tissue-engineered bone scaffold by $3 \mathrm{D}$ printing and biocompatibility study. Int J Clin Exp Med 8: 11777-11785, 2015.

34. Sa M and Kim JY: Effect of various blending ratios on the cell characteristics of PCL and PLGA scaffolds fabricated by polymer deposition system. Int J Precis Eng Man1 4: 649-655, 2013.

35. Shahrousvand M, Sadeghi GMM, Shahrousvand E, Ghollasi M and Salimi A: Superficial physicochemical properties of polyurethane biomaterials as osteogenic regulators in human mesenchymal stem cells fates. Colloids Surf B Biointerfaces 156: 292-304, 2017.

36. Folkman J and Moscona A: Role of cell shape in growth control. Nature 273: 345-349, 1978.

37. Uzer G, Pongkitwitoon S, Ete Chan M and Judex S: Vibration induced osteogenic commitment of mesenchymal stem cells is enhanced by cytoskeletal remodeling but not fluid shear. J Biomech 46: 2296-2302, 2013. 
38. Mathieu PS and Loboa EG: Cytoskeletal and focal adhesion influences on mesenchymal stem cell shape, mechanical properties, and differentiation down osteogenic, adipogenic, and chondrogenic pathways. Tissue Eng Part B Rev 18: 436-444, 2012.

39. Fu Y, Liu S, Cui SJ, Kou XX, Wang XD, Liu XM, Sun Y, Wang GN, Liu Y and Zhou YH: Surface chemistry of nanoscale mineralized collagen regulates periodontal ligament stem cell fate. ACS Appl Mater Interfaces 8: 15958-15966, 2016.

40. Thapa A, Webster TJ and Haberstroh KM: Polymers with nano-dimensional surface features enhance bladder smooth muscle cell adhesion. J Biomed Mater Res A 67: 1374-1383, 2003.

41. Karagkiozaki V, Vavoulidis E, Karagiannidis PG, Gioti M, Fatouros DG, Vizirianakis IS and Logothetidis S: Development of a nanoporous and multilayer drug-delivery platform for medical implants. Int J Nanomedicine 7: 5327-5338, 2012.

42. Affrossman S, Henn G, O'Neill S, Pethrick P and Stamm M: Surface topography and composition of deuterated polystyrenepoly (bromostyrene) blends. Macromolecules 29: 5010-5016, 1996.

43. Baker BM, Trappmann B, Wang WY, Sakar MS, Kim IL, Shenoy VB, Burdick JA and Chen CS: Cell-mediated fibre recruitment drives extracellular matrix mechanosensing in engineered fibrillar microenvironments. Nat Mater 14: 1262-1268, 2015.
44. Liao J, Wei Q, Zou Y, Fan J, Song D, Cui J, Zhang W, Zhu Y, $\mathrm{Ma} \mathrm{C}, \mathrm{Hu} \mathrm{X}$, et al: Notch signaling augments BMP9-induced bone formation by promoting the osteogenesis-angiogenesis coupling process in mesenchymal stem cells (MSCs). Cell Physiol Biochem 41: 1905-1923, 2017.

45. Deng Y, Liu X, Xu A, Wang L, Luo Z, Zheng Y, Deng F, Wei J, Tang $\mathrm{Z}$ and Wei S: Effect of surface roughness on osteogenesis in vitro and osseointegration in vivo of carbon fiber-reinforced polyetheretherketone-nanohydroxyapatite composite. Int J Nanomedicine 10: 1425-1447, 2015.

46. Spriano S, Sarath Chandra V, Cochis A, Uberti F, Rimondini L, Bertone E, Vitale A, Scolaro C, Ferrari M, Cirisano F, et al: How do wettability, zeta potential and hydroxylation degree affect the biological response of biomaterials? Mater Sci Eng C Mater Biol Appl 74: 542-555, 2017.

47. Ranella A, Barberoglou M, Bakogianni S, Fotakis C and Stratakis E: Tuning cell adhesion by controlling the roughness and wettability of 3D micro/nano silicon structures. Acta Biomater 6: 2711-2720, 2010.

48. Zhao G, Schwartz Z, Wieland M, Rupp F, Geis-Gerstorfer J, Cochran DL and Boyan BD: High surface energy enhances cell response to titanium substrate microstructure. J Biomed Mater Res A 74: 49-58, 2005.

This work is licensed under a Creative Commons Attribution-NonCommercial-NoDerivatives 4.0 International (CC BY-NC-ND 4.0) License. 